\title{
Finite element analysis of the Parthenon marble block-steel clamp system response under acceleration
}

\author{
Zacharias Vangelatos ${ }^{1}$, Michail Delagrammatikas ${ }^{2}$, Olga Papadopoulou ${ }^{2}$, Charalampos Titakis ${ }^{2}$, \\ Panayota Vassiliou ${ }^{2}$ \\ ${ }^{1}$ School of Mechanical Engineering, University of California, Berkeley, 2521 First Ave. Ca 94709, USA \\ 2 School of Chemical Engineering, National Technical University of Athens, 9 Iroon Polytechniou St. 15780, Athens, Greece
}

\begin{abstract}
Finite element analysis is employed to investigate the mechanical behaviour and failure scenarios of the marble block-steel clamp ancient masonry system utilised in the Parthenon (Athens Acropolis) under static loading analysis. The input data for the model are acquired by the laboratory testing of early 20th century restoration steel clamps, such as through tensile strength measurements and metallography, as well as bibliographic sources from various scientific fields (i.e. material properties, archaeometry, restoration, structural engineering and geology). Two different embedding materials (Portland cement mortar and lead), used for the nesting of the clamps, are examined under bending or stretching, induced by acceleration forces. The conservation status of the materials is taken into account by employing an intrinsic stress, as is the case when corrosion products build up in a confined space. The aim of this work is to provide a tool for the assessment of the conservation potential of the marble blocks in parts of the monument that require specific attention. Simulation results indicate the resilience of the Parthenon's structural system under most examined scenarios and highlight the importance of intrinsic stresses, the existence of which may lead to the fracture of the marble blocks under otherwise harmless loading conditions.
\end{abstract}

\section{Section: RESEARCH PAPER}

Keywords: Finite elements analysis; Parthenon; Steel corrosion; Marble; Restoration

Citation: Zacharias Vangelatos, Michail Delagrammatikas, Olga Papadopoulou, Charalampos Titakis, Panayota Vassiliou, Finite element analysis of the Parthenon marble block-steel clamp system response under acceleration, Acta IMEKO, vol. 10, no. 1, article 21, March 2021, identifier: IMEKO-ACTA10 (2021)-01-21

Editor: Carlo Carobbi, University of Florence, Italy

Received May 15, 2020; In final form August 25, 2020; Published March 2021

Copyright: This is an open-access article distributed under the terms of the Creative Commons Attribution 3.0 License, which permits unrestricted use, distribution, and reproduction in any medium, provided the original author and source are credited.

Corresponding author: Michail Delagrammatikas, e-mail: mdel@mail.ntua.gr

\section{INTRODUCTION}

The temple of the Parthenon on the Acropolis of Athens is considered to be the opus magnum of classical antiquity. This is mainly due to its ideological impact and its architectural and artistic value, which have influenced human civilisation, probably more than any other ancient monument, to the point that it provides the inspiration for the logo of the UN cultural organisation, UNESCO [1], [2]. The building of the Parthenon, designed by the architects Iktinos and Kallikrates, began in 447 $\mathrm{BCE}$, and the structure was completed by $438 \mathrm{BCE}$, while its sculptural decoration, designed by the sculptor Phidias, was completed in $432 \mathrm{BCE}$. What is probably less familiar to the general public is the technology that allowed this monumental structure to be built, sustain its structural integrity for 21 centuries and be able to remain, even in today's ruinous state, in a very good and recognisable condition almost 2,500 years after its construction. The latter is owed mostly to the laborious restoration programmes, almost constant during the most recent - nearly - 200 years of the existence of the modern Greek state, which are currently conducted by the Acropolis Restoration Service (YSMA) [3]. The durability of the monuments of the Acropolis of Athens is owed to the combination of natural materials of the highest quality, selected and worked not only by skilful artisans but by people who knew how to exploit their properties to their advantage, manmade materials comprising the most advanced technology of the era and elaborate masonry methods and techniques, which incorporated knowledge of previous experience both in the fields of aesthetics and of structural resilience in a zone of high seismicity.

The present study aims to highlight the importance of the conservation state of the original and restoration materials in terms of the response of the reinforced marble block system to 
earthquake-induced stresses. The approach of this work is interdisciplinary, mainly addressing conservation issues in relation to the monument materials rather than structural engineering.

The paper consists of six sections. Section 2 provides a general presentation on the structural system of the Parthenon and its history, emphasising the causes of the monument's structural decay and describing past restoration interventions, the consequences of which are the main subject of the paper. Most of the data for this section have been collected from the 'Study for the restoration of the Parthenon', edited by Korres and Bouras [4]. Section 3 consists of a brief bibliographic presentation of the seismicity in the Attica region and previous works on computer-assisted research into the mechanical performance of the Acropolis monuments using finite elements analysis. Section 4 presents the experimental setup for the laboratory testing of restoration steel clamps and for the finite elements analysis, while section 5 presents the results and discussion. The concluding section summarises the main points of this study and suggests future work.

\section{THE PARTHENON'S STRUCTURAL SYSTEM AND HISTORY}

\subsection{The structural system of the Parthenon}

The structural system of the Parthenon's load-bearing masonry comprises Pentelic marble blocks, interconnected by a system of steel clamps and dowels, embedded in lead without the use of any mud, mortar or cementitious binding material (Figure 1); thus, it can be described as a reinforced marble system. Each individual marble block has been cut to the correct size and shape (a quasi-rectangular parallelepiped), tailored to satisfy the refinements of the architectural design and compensate any visual distortions. Each block has been smoothed to achieve tight contact between the entire surface of the contact areas of the blocks. The contact between the marble blocks is so tight that, even today, water cannot penetrate the non-disturbed parts of the masonry. The ancient marble cutters, where possible, took advantage of the anisotropy of the natural material and oriented the longest axis of the marble crystallites in the direction where the strongest mechanical strength was required [4]. The blocks were anchored to each other using steel joints nested in specially carved cavities and embedded in molten lead, which provided a means of mechanical continuity and a ductile buffer material between the steel and the marble, while also acting as a protective environment against steel corrosion. 'Double-T'-shaped clamps were used to join the marble blocks belonging to the same horizontal level, while smaller dowels were used to join the marble blocks to the ones above and below. The steel-clamp anchoring system did not connect all parts of the monument uniformly but was designed to create rigid areas with similar loadbearing characteristics, while allowing for different areas to perform independently [4]. The steel clamps were produced by cladding and folding layers of low-carbon hypoeutectoid steel and ferritic iron with a very low impurities content, which allowed for better corrosion resistance. The metal joints were not designed to bear the static loads but to contribute to the response of the system in case of deformation due to subsidence or an earthquake. The thickness of the steel clamps (of typical crosssection dimensions of between $0.3 \times 3.0 \mathrm{~cm}$ to $0.5 \times 5.0 \mathrm{~cm}$ ) was small compared to the width of the nesting cavity and, thus, to the thickness of the moulted lead as well as to the thickness of the surrounding marble. This design ensured that if the marble blocks moved apart, it would be the clamps
, not the marble, that would fail [4]. Similar structural design and reinforcement technology for stone masonry has also been adopted in several other monuments around the world. Corrosion analyses on ancient iron clamps from the Gupta temple at Eran in Madhya Pradesh (India), dating from the $5^{\text {th }}$ century CE [5], as well as metallurgical analyses on iron crampons from masonry complexes in a palace and two temples in Angkor (Cambodia), dating from the Khmer Empire between the $10^{\text {th }}$ to $13^{\text {th }}$ centuries CE [6], offer valuable information on the properties and preservation state of ancient iron-based architectural elements.

\subsection{Structural decay of the Parthenon until the $20^{\text {th }}$ century}

This masonry system proved to be very resilient to local seismicity, ensuring the structural integrity of the monument for more than 2,000 years. There have been, in fact, several severe earthquakes in the Attica region, and the first documented damage to the Parthenon occurred during an earthquake in 426 5 BCE, during which the marble blocks in the north-east corner were shifted about $2 \mathrm{~cm}$ northwards [4]. Regardless, all the severe damage to the structural elements of the monument is due to anthropogenic causes. The first case of severe damage to the monument is believed to have happened between the $4^{\text {th }}$ and $5^{\text {th }}$ centuries $\mathrm{CE}$, and even though there are no historical records of this event, the pathology of the building materials testifies to thermal damage caused by a fire, which deprived the monument of its original roof and many of the internal architectural elements. Nevertheless, the structural integrity of the Parthenon was preserved until $1687 \mathrm{CE}$, when a mortar bomb, launched during the siege of the Ottoman guard residing on the Acropolis by the troops of the Venetian Captain-General, and later, Doge, Francisco Morosini, penetrated the roof of the Parthenon, causing the ammunition stored inside to explode. This explosion resulted in the catastrophic collapse of most of the long side walls and peristyles. The lower-level marble blocks of the Parthenon, and of the other classical monuments on the Acropolis, suffered a different catastrophic decay in the course of the Greek revolution. During the siege of the Acropolis (1821-1822), the besieged Ottoman garrison broke off the corners of many of the marble blocks in order to gain access to the lead to use it as ammunition. The created voids and cracks allowed the penetration of water, which reached the steel joints and induced corrosion on the steel clamps.

The aforementioned events were not the only cases of severe damage being caused to the Parthenon, but they had the most

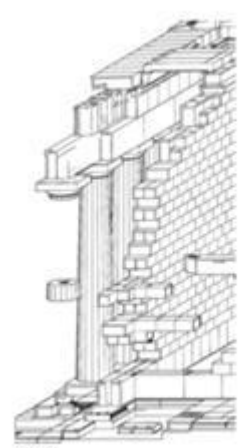

(a)

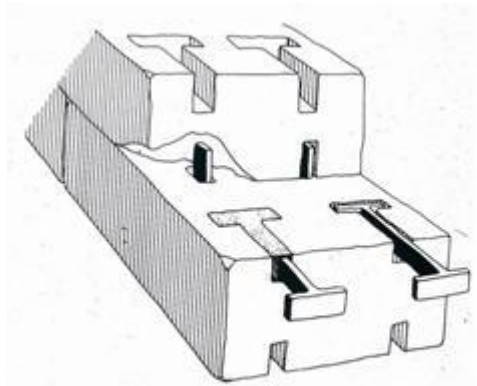

(b)
Figure 1. (a) A schematic presentation of a wall of the Athens Parthenon; (b) A schematic presentation of the application of steel double T's and dowels, embedded in cast lead, to connect the marble blocks [7]. 
impact on its structural integrity. Acts of vandalism by the early Christians and acts of looting during the period between the 17th and early 19th centuries by visiting art collectors had already deprived the monument of a significant amount of sculptural ornamentation, while the looting by Lord Elgin of large parts of the frieze, which was sculpted on structural marble blocks, caused further structural damage. In addition to this accidental or malicious damage, it should be noted that the building had undergone several restorations and alterations corresponding to its different uses, mainly as a place of worship. The Parthenon (i.e. the house of the virgin) served as a pagan temple to the goddess Athena, as a Christian church dedicated, most of the time, to the Virgin Mary 'Athiniotissa' and as a Muslim mosque. After the 1687 catastrophe, a new, small mosque was built inside the ruins of the temple, using much of the original debris as building material, while many other such structures were erected on the Acropolis.

\subsection{The restoration of the Parthenon as an ancient monument}

This was the situation of the Athens Acropolis monuments when the newly founded Greek state began the task of restoration according to the restoration trends of the era. These mainly consisted of the purification of the classical monument from all later modifications. The first large important restoration programme of the Parthenon took place between 1842 and 1845 and was part of a large-scale excavation plan that included the demolition of later construction, partly to reclaim the incorporated ancient building material but also serving the ideological context of advocating ancient Greek civilisation, which constituted a state policy. Fortunately, the restoration principles that were employed by the Greek state never followed the fashion of complete reconstruction but aimed to restore the ruins using as much of the original material as possible. This policy can be attributed to the fact that the Acropolis monuments were no longer considered as a functional monumental complex, but as a ruinous ancient monument serving as a symbol of the rebirth of the nation.

The largest restoration works in the past took place between 1898 and 1933 under the supervision of an engineer, Nikolaos Balanos, who, against recommendations to use brass reinforcement elements, used restoration double- $T$ or squarebracket-shaped steel clamps of different qualities, mostly embedded in Portland cement mortar, along with large iron beams and elements of reinforced concrete, where convenient. The technique of moulding lead was sporadically used, while ancient clamps that were in a good state were reused. The restoration clamps were significantly thicker than the ancient clamps, and their metallurgical characteristics varied significantly during the course of the works. The choice of embedding the joints in Portland cement mortar proved to be another unsuccessful choice, as just a few years after the application, the steel showed severe corrosion. Unlike the lead, the porous mortar did allow the water to reach the iron clamp, while the restored marbles did not have perfect contact between them, allowing the water to penetrate the interface. As a result, iron corrosion products, mostly oxides and hydroxides, which have larger crystal volumes than the iron alloy, grew producing stresses, which led to the excessive cracking of the marble blocks. The restoration works under Balanos are considered to be below the standards of their era, lacking in both design and documentation, resulting in extensive damage to the monument's original material. However, from a strictly structural point of view, these interventions allowed the monument to withstand the strong 1981 earthquake with minimal damage [4].

The next large-scale restoration project on the Acropolis of Athens started in 1975, when the interdisciplinary scientific committee (ESMA) undertook the task of providing scientific support to the Acropolis Restoration Service. One of the measures proposed by ESMA was the substitution of steel by titanium alloy joints [8]-[10], which have better physicochemical characteristics and are not prone to corrosion in natural environmental conditions. The surrounding material that binds the joints to the marble is a cement mortar comprised of Aalborg white cement and quartz sand. Hydraulic grouts based on Aalborg white cement and finely ground natural pozzolan are being used for the consolidation of broken parts [11]. Although, by the end of the current restoration works, most of the previous restoration clamps will have been removed, the parts of the monument that are still standing in their original position will continue to be connected by the authentic steel clamps embedded in lead.

\subsection{Emergence of atmospheric pollution in the mid-1950s and the acceleration of structural element decay}

Additional causes of anthropogenic damage that emerged in the $20^{\text {th }}$ century are related to atmospheric pollution as a result of the industrialisation of Athens in the mid-1950s and the unsound use of materials during the restoration on the monuments before 1933 .

Both marble and steel joints (original and restoration) were, inevitably, exposed to heavy atmospheric pollution during the period 1955-1985 due to the rapid industrialisation of Athens and the extensive use of high sulphur content fuels. Between 1984 and 1985, the main atmospheric pollutants, according to the monitoring data, were soot (elemental $\mathrm{C}$ ), particulate matter, $\mathrm{NO}_{2}, \mathrm{SO}_{2}, \mathrm{CO}_{2}, \mathrm{CO}, \mathrm{O}_{3}, \mathrm{CFCs}$ (Chloro-Fluoro-Carbons) and PANs (Peroxy-Aketyl-Nitrates). All these species were detected at high levels. The dry and wet pollutant precipitation, in the form of particulate matter and acid rain, caused extensive sulphation of the marble surface and also accelerated the corrosion rate of the steel clamps. Two different sub-groups of restoration clamp samples, which were collected from 1952 1954 from demolished buildings and during interventions at the Erechtheion from 1979-1980, and which were examined by founding ESMA member, Prof. Skoulikides, testified to an increase in the corrosion rate of $25-30 \%$, attributed to the impact of industrial pollution [10].

More recent studies involving quantitative measurements of atmospheric pollutants at the centre of Athens were published in the 1990s. Aerosol species (anions, such as $\mathrm{Cl}^{-}, \mathrm{SO}_{4}{ }^{2-}, \mathrm{NO}_{3}{ }^{-}$and $\mathrm{NH}_{4}{ }^{+}$, and cations, including $\mathrm{Na}^{+}, \mathrm{K}^{+}$and $\mathrm{Ca}^{2+}$ ) were detected at moderate levels, and gaseous pollutants (mainly $\mathrm{HCl}$ and $\mathrm{HNO}_{3}$ acids) were rather high [12], [13]. Cleaner fuels and pedestrianisation in the vicinity of the Acropolis hill have significantly reduced the impact of atmospheric pollutants on the monuments since the early 2000s.

\section{SEISMIC ACTIVITY IN THE ATTICA REGION AND FINITE ELEMENT ANALYSIS OF THE PARTHENON'S STRUCTURAL SYSTEM RESPONSE}

Greece lies on the collision plate boundary between the African and the Eurasian tectonic plates; thus, it is a region of high seismicity. According to the Greek Seismic Regulation, Attica, the province in which Athens is situated, is ranked in the 
second of four zones on a scale of increasing seismic activity. Thus, modern structures are designed to be able to withstand an effective peak acceleration (EPA) of $0.16 \mathrm{~g}$, where $\mathrm{g}$ is the gravitational acceleration [14]. During the last severe earthquake that hit Athens in September 1999, the peak ground acceleration (PGA) recorded varied between 0.044 and $0.511 \mathrm{~g}$, while amplification analysis has estimated values as high as $0.7 \mathrm{~g}$ [15].

The earthquake response of many classical monuments in Greece, including the Parthenon, has been a growing field of study over the last decades. Many research groups have conducted computer-aided simulations, based on finite element models, in order to assess the local and overall vulnerabilities of the marble structures (either intact or damaged) during repetitive loading and to predict potential failure conditions [16]-[20] According to the relevant literature, the mechanical performance of complex marble structures requires the design of both simplified models (sub-assemblies of the system) and structural models of the whole structure [17]. The discontinuity of masonries due to multiple structural marble elements along with iron clamps and joints and other original or restoration materials (lead, cement-based mortars, etc.) at their interface, enhances the challenge of realistic simulations. The effect of past restoration interventions on the monument's mechanical performance as well as the evaluation of new materials to be used in on-going restoration works (titanium clamps and white cement mortar) has also been studied in some cases [18], [19]. Psycharis et al. [17] investigated the dynamic earthquake impact on the Parthenon's marble masonry via a simplified sub-assembly model (section of a wall) and a general structural model of the partially restored monument. These two numerical models were run with and without taking into consideration the metal reinforcing elements. Among the most important findings of this work were (a) the overestimation of the maximum displacements by the simplified model and (b) the lower residual deformation in the presence of the metal clamp connectors between the marble blocks, but the significantly higher rocking response (larger maximum displacement). Pasiou et al. [19] studied the stress fields that developed after static shearing loading on the Parthenon's restored epistyles, using a numerical model that describes a small system of marble walls-titanium connectors-cement mortar. High mechanical impact was observed around the interface of the two epistyles in contact, near the metal clamps, and the effect of the relieving space between the marble and the metal clamp was also investigated. Another finite element analysis, performed on the restoration of the Parthenon's detached epistyle parts by Ganniari-Papageorgiou [18], focused on the role of the cementitious layer between the marble and the bolted titanium bars during bending, which is found to significantly reduce the strain discontinuity that was observed locally near the titanium clamp. Toumbakari analysed the failures of the northern wall orthostate and focused on the role of the connection elements (clamps and dowels) in the observed pathology [20].

\section{EXPERIMENTAL}

\subsection{Laboratory testing}

For the scope of this research, three steel clamps, two double$\mathrm{T}$ shaped (S.200, S.214) and one square-bracket shaped (S.245), all previously used in restoration works executed under the supervision of Balanos, were provided to the authors by YSMA. The clamps were submitted to a series of chemical analyses, mechanical tests, microscopic evaluation and electrochemical corrosion testing.
Table 1. Molar concentrations of ionic species and properties of the synthetic electrolyte.

\begin{tabular}{lc}
\hline $\mathrm{SO}_{4}{ }^{2-}(\mathrm{mol} / \mathrm{L})$ & 0.050 \\
$\mathrm{NO}_{3}{ }^{-}(\mathrm{mol} / \mathrm{L})$ & 0.025 \\
$\mathrm{Cl}^{-}(\mathrm{mol} / \mathrm{L})$ & 0.008 \\
$\mathrm{HCO}_{3}{ }^{-}(\mathrm{mol} / \mathrm{L})$ & $5 \cdot 10^{-5}$ \\
Total salt concentration $(\% \mathrm{w} / \mathrm{v})$ & 0.97 \\
lonic conductivity $\left(\mathrm{mS} / \mathrm{cm}\right.$ at $\left.24{ }^{\circ} \mathrm{C}\right)$ & 11.29 \\
$\mathrm{pH}\left(\right.$ at $\left.24{ }^{\circ} \mathrm{C}\right)$ & 5.5 \\
\hline
\end{tabular}

Elemental chemical analyses were conducted using an ARL3460 automatic optical emission spectrometer (OES), and tensile tests were performed with a Roell Amsler System MFL UPN 1000 apparatus at the Halyvourgiki Inc. laboratory on specimens cut out of the three clamps (S.200, S.214 and S.245). The assessment of the experimental data for the calculation of the mechanical properties of the clamp specimens was performed in accordance with the EN 10080 (2005) standard, taking into consideration the actual geometric characteristics of the specimens. Micro-hardness tests were performed using an Instron Wolpert GmbH V-testor 4021. Fracture surfaces were examined by means of scanning electron microscopy (SEM), using a FEI 200 SEM equipped with a tungsten filament and an Everhart-Thornley Detector. Metallographic observations were performed on cross sections, polished to $0.25 \mu \mathrm{m}$ and etched by Nital $2 \%$ ethanol reagent for $30 \mathrm{~s}$ using a Leitz Aristomet optical microscope under crossed Nicols.

The potentiodynamic electrochemical measurements on the corroded surfaces of the three steel clamps under investigation were conducted using a typical three-electrode cell configuration in $350 \mathrm{~mL}$ electrolyte volume, connected to a GAMRY potentiostat. The clamp specimen was employed as the working electrode, an $\mathrm{Ag} / \mathrm{AgCl}$ ( $\mathrm{ASE}_{3.5 \mathrm{M} \mathrm{KCl}}$ ) electrode as a reference and a Pt wire as the auxiliary electrode. The control of all test parameters and the subsequent analyses/modelling of the experimental data were performed using CMS 100 software. The specimen's free corrosion potential was recorded for 30 minutes under open-circuit conditions, and then a Tafel curve was acquired at a scan rate of $1 \mathrm{mV} / \mathrm{s}$. The potential range of the anodic sweep was set at open-circuit potential (OCP) $\pm 200 \mathrm{mV}$.

The city of Athens exhibits environmental conditions typical of an urban-industrial-marine environment. For that reason, a synthetic electrolyte representative of the wet precipitation in Athens city centre was produced in the lab, based on atmospheric pollution data collected in this particular geographical area in 1998 [13]. This aqueous electrolyte mixture contained dissolved sulphates, nitrates, chlorides and carbonates at suitable concentrations. The $\mathrm{pH}$ of rainwater in Athens was measured as being between 4.5 and 5.5 during the period 1995-2000 [10]. The synthetic electrolyte $\mathrm{pH}$ is on the upper limit of this range. The molar concentration of all ionic species and properties of the electrolyte are presented in Table 1.

\subsection{Computational analysis}

All the finite element analysis simulations were performed with the multi-purpose finite element ANSYS software (Workbench 18.0). ANSYS enables the design of complex components to depict the geometry of a system (CADs), utilising ANSYS Design Modeller. In addition, it discretises the structure to finite elements, estimating the mechanical behaviour of the system. It can be utilised to estimate the deformation of the structure under static loading and modal analysis. It was 
Table 2. Measured chemical composition and mechanical properties of the three steel clamps in comparison with the ancient clamps.

\begin{tabular}{|c|c|c|c|c|}
\hline Composition $(\% \mathrm{w} / \mathrm{w}) /$ Properties & Clamp S.200 & Clamp S.214 & Clamp S.245 & Ancient Clamps* \\
\hline Carbon & 0.019 & 0.085 & 0.008 & $0.017-0.582$ \\
\hline Manganese & 0.454 & 0.039 & 0.007 & $0.001-0.064$ \\
\hline Sulphur & 0.022 & 0.010 & 0.003 & $0.006-0.007$ \\
\hline Chromium & 0.024 & 0.003 & 0.002 & $0.004-0.017$ \\
\hline Other minor elements & 0.169 & 0.141 & 0.076 & $0.14^{* * *}$ \\
\hline Iron balance & 99.312 & 99.722 & 99.904 & $99.75^{* * *}$ \\
\hline Vickers hardness (HV) & 121.5 & $117.8 / 110.5^{* *}$ & 92.4 & $\max .107$ \\
\hline Tensile yield strength (MPa) & $* * * *$ & 240 & 248 & - \\
\hline Ultimate tensile strength (MPa) & 410 & 328 & 322 & $\max .380$ \\
\hline Young's modulus E (GPa) & $* * * *$ & 50 & 40 & - \\
\hline Strain \% & 17.1 & 11.4 & 18.9 & - \\
\hline
\end{tabular}

employed for the modelling of the mechanical behaviour of the clamp that was representative of those that were used in the Acropolis of Athens monuments restoration between 1898 and 1933. In our case study, ANSYS was used for static analysis under acceleration effects caused by loading conditions that emulated an earthquake. A characteristic discretised CAD of the system is presented in Figure 2. The system was discretised by 10-node, tetrahedral finite elements with 45,924 elements and 76,025 nodes. The various parts comprising the clamp (steel-lead or steel-cement mortar) were 8-node surface elements assigned to the interfaces of the constituent parts. The potential contact between the clamp and the marble block was modelled as simple friction without sliding. The high density of the mesh grid was designed to accurately predict the generated stresses. It must be noted that we focused on the mechanical behaviour of an individual structural block of the system. While in other reports the whole monument was modelled, this significantly decreases the precision of the numerical simulations due to the high computational cost. Therefore, a symmetric unit cell of the masonry system was modelled, comprised of two successive half marble blocks that were in contact with each other and connected by a clamp and the embedding material in the nest.

Three different physical models were tested. The first two consisted of a non-corroded steel clamp (7.6 mm thickness) embedded in the marble nesting using Portland cement mortar or lead as binding material. The third physical model consisted of a corroded steel clamp on which the growth of the corrosion products had induced a tensile stress in the lead and the half marble blocks. This last model is more challenging since the determination of the actual mechanical properties of corroded steel reinforcement continues to be an open challenge in the

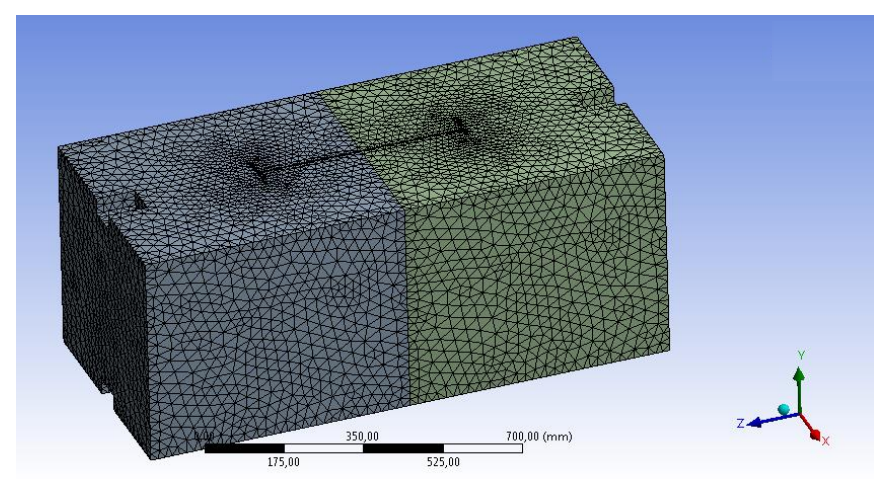

Figure 2. Marble block mesh grid for the finite element analysis. fields of corrosion science and structural engineering [21]-[23]. The aim was to investigate the effects of the corrosion phenomena on the mechanical behaviour of the system under bending loading. The physical model for this simulation was designed by equating the space that would become available as a result of the elastic deformation of the surrounding materials under a stress of $5 \mathrm{MPa}$, plus the reduction of the metal core of the clamp to the corresponding thickness of a dense layer of lepidocrocite with a density of $4,000 \mathrm{~kg} / \mathrm{m}^{2}$. The stress of $5 \mathrm{MPa}$ was chosen as corresponding to the lowest limit of the ultimate tensile stress of Pentelic marble. Any more stress could lead to the cracking of the marble caused by the crystallisation pressure of the corrosion products without any external loading action, causing irreversible damage, at least from the perspective of monument conservation.

The imposed loading consisted of a one-way acceleration enforced for $1 \mathrm{~s}$, corresponding to a $0.25 \mathrm{~Hz}$ frequency, which is in the range of local earthquakes. The finite element analysis was performed for three acceleration values: $0.3 \mathrm{~g}, 0.6 \mathrm{~g}$ and $1.2 \mathrm{~g}$, corresponding to a typical local PGA and its two- and four-fold products, respectively. The direction of the acceleration was simulated for two different scenarios. In the first scenario, the direction of the acceleration was parallel to the axis of the clamp (parallel to the $z$ axis of Figure 2). In this scenario, referred to as stretching, the left half marble block was fixed, while the right was free to move. In the second scenario, referred to as bending, the acceleration was perpendicular to the clamp axis (parallel to the $x$ axis) and imposed on the interface of the two marble blocks. The outer unit cell surfaces on the xy plane, which correspond to the middle of the integral marble block, as well as the dowel fittings, were only allowed to rotate; otherwise, the system would sustain a rigid body motion, prohibiting the effective simulation of stresses and strains. The mechanical properties required for the model are density, Young's modulus of elasticity, Poisson's ratio, tensile yield strength and ultimate tensile strength, as derived from the stress-strain curves. Each simulation took approximately 8 hours of computer time.

\section{RESULTS AND DISCUSSION}

\subsection{Chemical composition \& mechanical properties}

The OES results, briefly presented in Table 2 , indicate that all three samples have a carbon concentration between 0.008 and $0.085 \%$; the S.214 clamp has the highest C content $(0.085 \%)$. According to the thermodynamic data on steels (metastable Fe- 


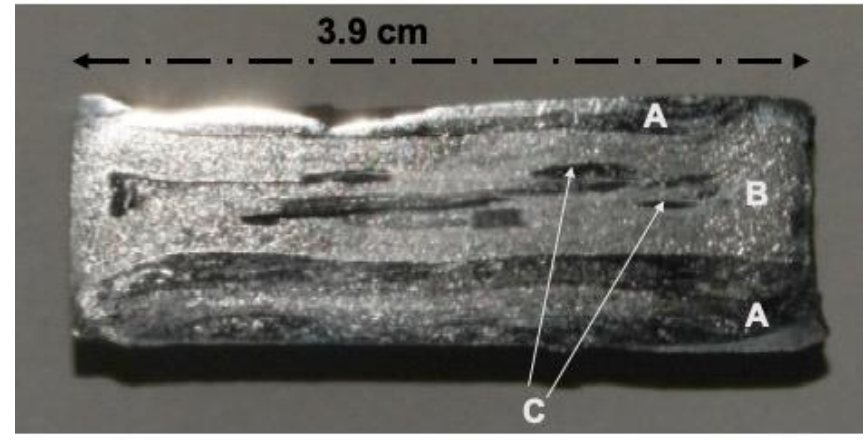

Figure 3. Macrophotographic documentation of the clamp S.214 cross section. Marked areas $\mathrm{A}$ and $\mathrm{C}$ correspond to external and internal hypoeutectoid steel zones, while B corresponds to the low-carbon iron zone.

C diagram [24]), S.214 can be identified as hypoeutectoid plain carbon steel because its $\mathrm{C}$ content is between 0.025 and $0.8 \%$. Clamps S.200 and S.245, with a C content below $0.025 \%$, although typically low-alloy steels, should be categorised as irons due to their ferrite matrix [24]. These results are in accordance with the ancient low-carbon T-clamps analysed by Varoufakis [25].

All the examined reinforcement clamps exhibit very low hardness, and their stress-strain curve exhibits the typical patterns of ductile fracture. The measured ranges of hardness, tensile strength and \% strain are given in Table 2 . These values approximate relevant measurements by Varoufakis [25] on ancient T-clamps. The reduced hardness is attributed to the low C and Si concentrations. In the case of clamps S.214 and S.245, the tensile yield strength was also recorded as well as the Young's modulus. Upon fracture, the clamps are more or less prone to a ductile fracture mechanism.

Of the three examined steel clamps, S.214 was selected for more detailed examination because of its extensive microstructure heterogeneity and its unique resemblance to the ancient material characteristics [26]. As can be observed on a polished cross section (Figure 3), the manufacturing process resulted in a composite material. It is evident that hypoeutectoid steel and the low-carbon iron-alloy sheets were cladded and folded. The metallographic observations after chemical etching reveal the various microstructure characteristics of the distinct zones A, B and C, marked on Figure 4. The recrystallised grains of all the zones testify to the absence of intense cold working processes during the manufacturing process, which is in accordance with the low-hardness values measured. The grain orientation of the thin superficial layer above zone A, not presented in the two optical microscope photographs, indicates a final mild work hardening process of the surface. The fractography of the S.214 clamp provides a variety of ductile fracture patterns, which is characterised by dimples (Figure 5). Some areas exhibit a more brittle fracture type.

The electrochemical tests served the purpose of assessing the relative electrochemical reactivity of these restoration metals when exposed in an electrolyte that approaches the wetness conditions of their original corrosion environment and could enable corrosion reactivation. In addition, these measurements enable a more complete characterisation of the restoration metals and their performance.

The electrochemical behaviour of the corroded surfaces of the three steel clamps is in good agreement with the findings of the chemical and metallurgical characterisation and the available literature data. Higher carbon and sulphur content in the iron
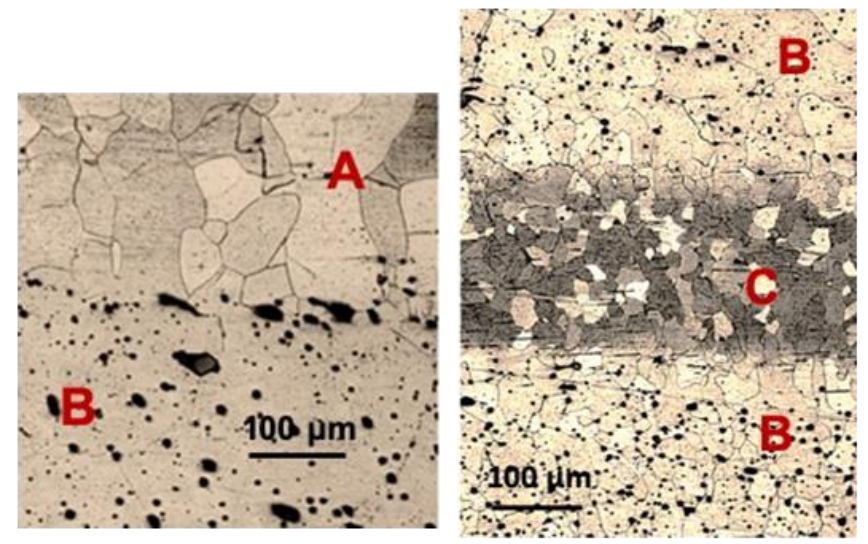

(a)

(b)

Figure 4. Optical microscope photograph (x 100) of the S.214 clamp cross section, chemically etched with $2 \%$ Nital reagent. (a) Interface of the hypoeutectoid steel zone A (top) and the low-carbon iron alloy zone B (bottom), inside which MnS inclusions are visible. (b) Hypoeutectoid steel zone $\mathrm{C}$ interposed between two low-carbon iron alloy $\mathrm{B}$ zones.

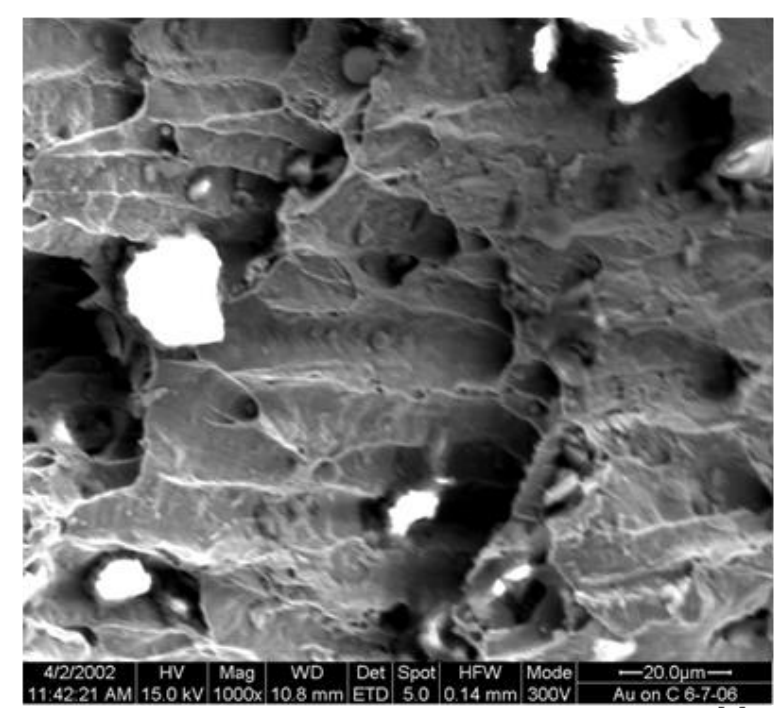

(a)

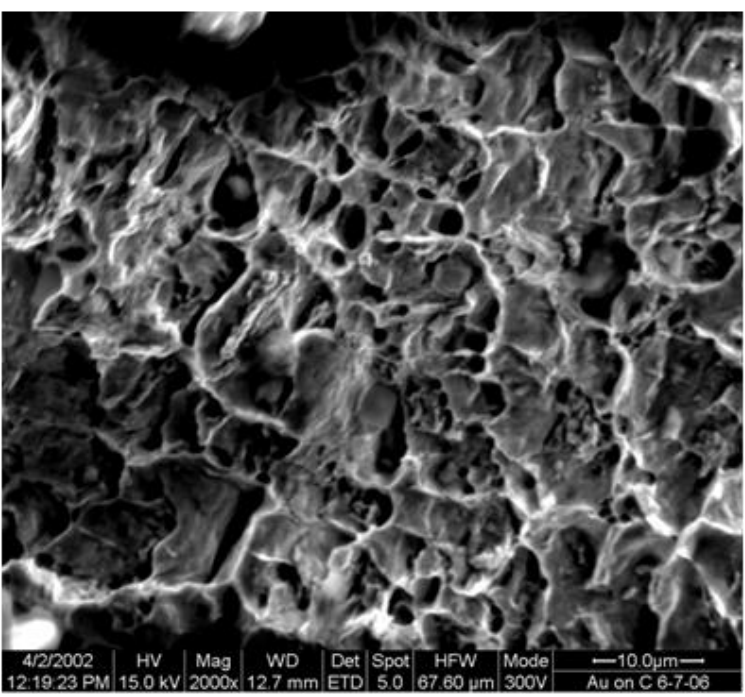

(b)

Figure 5. Secondary electron micrographs of clamp S.214 fracture surfaces (a) x 1000 and (b) x 2000, acquired by SEM. Characteristic ductile fracture dimples cover most of the fracture surface. 
(a)

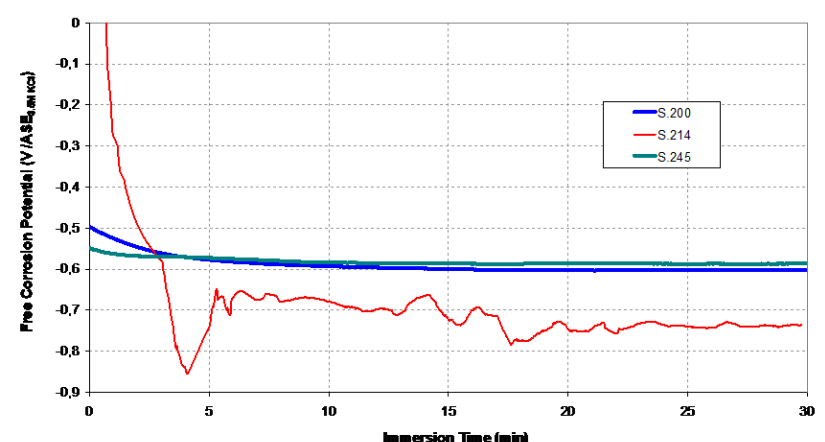

(b)

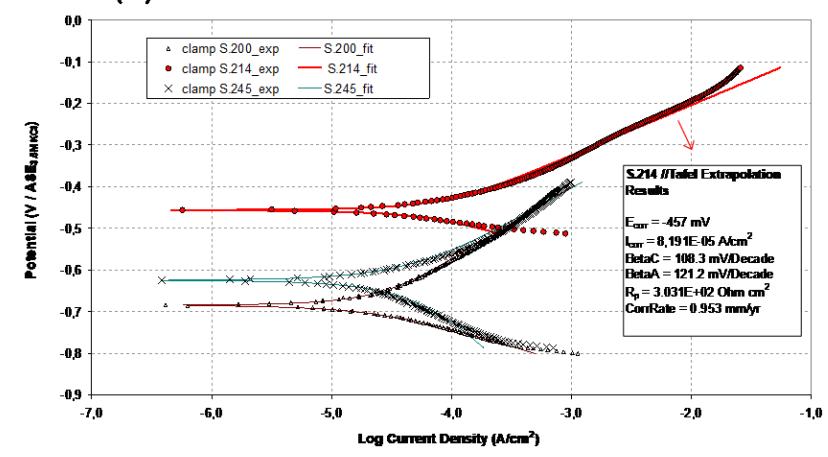

Figure 6. (a) OCP recording for steel clamp S.214 for 30 minutes, before the linear polarisation test, compared to the two low-carbon clamp samples, S.200 and S.245; (b) Tafel curve of steel clamp S.214 and fitted model by linear extrapolation method compared to the two low-carbon clamp samples, S.200 and S.245. The tests were conducted in the $0.97 \% \mathrm{w} / \mathrm{w}$ synthesised atmospheric pollutants electrolyte.

matrix contribute to a higher susceptibility to corrosion [25]. Clamp S.214's surface, in its as-received state, was covered with some typical iron corrosion products. This corrosion layer delayed the uniform wetting of the metal surface, and this is evident by the fluctuations observed in the OCP curve during the initial 20 minutes of immersion (Figure 6). The final equilibrium potential corresponds to an electrochemically active state, i.e. the corrosion process is re-activated. Clamps S.200 and S.245 exhibit similar trends, and in both cases, the free corrosion potential is stabilised very quickly at more positive (noble) potentials. The 5-minute and 30-minute OCP values are presented in Table 3 . The results of the subsequent linear polarisation tests show that S.214's surface, which is of higher C concentration and metallurgical heterogeneity, is more prone to further corrosion, exhibiting the highest corrosion current density ( $\left.I_{\text {corr }}\right)$ and annual corrosion rate and the lowest polarisation resistance $\left(R_{\mathrm{p}}\right)$ (Table 3$)$. S.214's corrosion rate is two times higher than that of S.245, the pure iron clamp, and nearly four times higher than S.200. The best electrochemical
Table 3. Free corrosion potential values recorded under OC conditions before the potentiodynamic tests, and Tafel extrapolation results calculated for the three clamp samples after linear polarisation in the $0.97 \% \mathrm{w} / \mathrm{w}$ atmospheric pollutants electrolyte.

\begin{tabular}{lccc}
\hline Measured Property & S.200 & S.214 & S.245 \\
\hline 5 min OCP (mV/ ASE) & -578 & -743 & -573 \\
$30 \mathrm{~min}$ OCP (mV/ ASE) & -602 & -736 & -586 \\
$\mathrm{E}_{\text {corr }}(\mathrm{mV} / \mathrm{ASE})$ & -685 & -457 & -625 \\
$\mathrm{I}_{\text {corr }}\left(10^{-5} \mathrm{~A} / \mathrm{cm}^{2}\right)$ & 2.28 & 8.19 & 4.38 \\
$\mathrm{R}_{\mathrm{p}}\left(10^{2} \mathrm{Ohm} \mathrm{cm}{ }^{2}\right)$ & 10.94 & 3.03 & 9.85 \\
BetaC $(\mathrm{mV} /$ decade) & 85.9 & 108.3 & 254.7 \\
BetaA (mV/decade) & 173.6 & 121.2 & 0.953 \\
Corrosion Rate (mm/year) & 0.266 & 0.953 & 0.509 \\
\hline
\end{tabular}

properties relating to corrosion are observed for clamp S.200 and are attributed to the addition of chromium in the alloy.

\subsection{Computational modelling}

Computational modelling has been performed using as input parameters the experimental values obtained for the S.214 clamp and bibliographic data for all other materials (Table 4).

These simulations aim to investigate the effect of either lead or Portland cement mortar as well as stresses generated by corrosion-product growth in the clamp assembly under either bending or stretching caused by the acceleration force of the marble blocks. Regarding the loading conditions, the stresses that develop on the metal clamp-marble block system during earthquakes depend on their orientation in the walls of the structure. Thus, for a north-south direction earthquake, the walls that are parallel to this direction will be affected by tensile stresses, while the perpendicular ones will be subjected to shearing or bending stresses. When a body is stressed by tensile and shearing stresses, these types of stress can be converted to what is called equivalent von Mises stress, which is considered to be a tensile stress. This is the measure that determines whether a part of the structure has either reached the plastic zone (e.g. ductile) or has surpassed the yield point and will fracture (e.g. brittle). In any case, when the von Mises stress is higher than the tensile yield strength, failure occurs. A representative deformed configuration of the simulation results under bending, presented in Figure 7, is indicative of the morphology of the generated stress. The different colours represent variations in the stress field of both the clamps and the marble blocks. Even though the stresses that develop on the marble blocks in the simulation presented in Figure 7 are significantly lower than the tensile strength of the marble, their distribution reaches its maximum near the dowels. This observation is in accordance with the damage caused to the lower parts of the Parthenon and to the models published by Toumbakari [20]. The fact that the presented results are congruous with the reported ones shows the validity of our model.

Table 4. Model input data.

\begin{tabular}{|c|c|c|c|c|c|}
\hline Input Property & Steel Clamp & Lead & Pentelic Marble & Cement Mortar & Corrosion Products \\
\hline Density $\mathrm{d}\left(\mathrm{kg} / \mathrm{m}^{3}\right)$ & $7.85 \cdot 10^{3}$ & $1.13 \cdot 10^{4}$ & $2.71 \cdot 10^{3}$ & $2.40 \cdot 10^{3}$ & $4.00 \cdot 10^{3}$ \\
\hline Young's modulus E (GPa) & 50 & 14 & 49 & 48 & 9.0 \\
\hline Tensile yield strength $\sigma_{y}(\mathrm{MPa})$ & $2.5 \cdot 10^{2}$ & 18 & - & - & - \\
\hline Ultimate tensile strength $\sigma_{\mathrm{y}}(\mathrm{MPa})$ & $3.5 \cdot 10^{2}$ & 27 & 15 & 5.0 & 1.5 \\
\hline Ultimate compressive strength $\sigma_{y}(\mathrm{MPa})$ & - & - & 114 & 37.5 & 15.0 \\
\hline
\end{tabular}




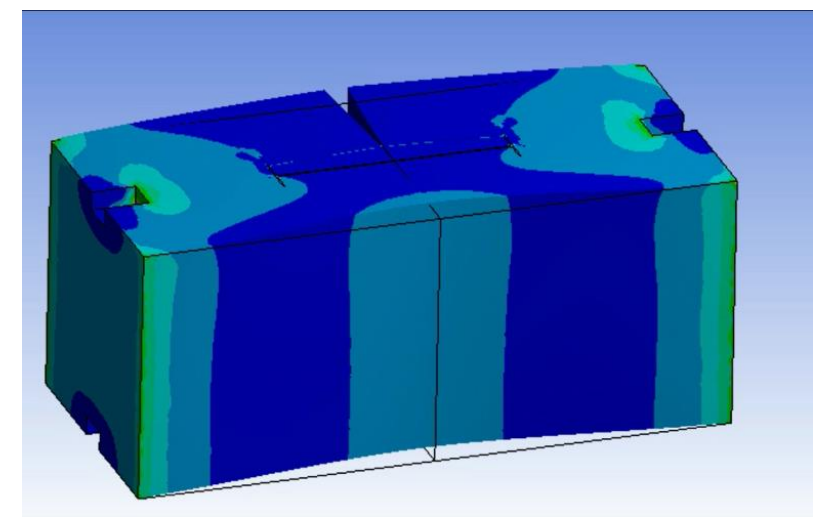

Figure 7. Marble block-steel clamp system. Equivalent von Mises stress: bending.

Table 5 summarises the maximum von Mises stress that was obtained for each whole system and for the marble in each system under each loading condition. The first part of the table presents the maximum stress values that develop in the unit cell regardless of the exact material that these are enforced on, and the second part presents the maximum stress that develops on the marble blocks. The third part of the table presents the linear coefficients between maximum stress developed and acceleration imposed and the coefficients of variation, calculated by regression analysis, while the fourth part presents the estimated maximum stress values for the EPA of $0.16 \mathrm{~g}$, according to the linear coefficients. The results predict that the most catastrophic loading condition for the system is stretching. The reason is that during this deformation, the marble block applies high stress to the edges of the clamp, leading to high stress concentration. However, it should be pointed out that the free movement of the marble block presupposes the absence of other supports for this particular block, such as is the case in corner blocks or corner groups of blocks where the accelerated mass would be manifold. This scenario could describe the pathology induced by the 426 5 BCE earthquake, during which the stresses were relieved by the displacement of the marble blocks, allowed due to the thin cross section of the original clamps. Bending does not cause such high stress concentration because the inertia of the marble block is significantly higher during bending, which obstructs the relative motion of the blocks.
Before discussing the results further, it should be noted that the main criteria of failure in the simulations is the possibility of inducing damage to the marble blocks. The embedding materials (Portland cement mortar or lead) are considered as sacrificial, while stresses on the steel clamp do not reach magnitudes near the tensile yield strength. This occurs even at the significantly lower Young's modulus that was experimentally measured (50 $\mathrm{GPa}$ ) for the steel. To put this value into perspective, typical values of Young's modulus for stainless steel are in the region of $200 \mathrm{GPa}$. However, Pentelic marble is a natural anisotropic material and, as such, its properties, such as tensile strength and Young's modulus, depend on the direction of the imposed loading or the defects that naturally occur. Thus, while the ultimate tensile strength of the marble was fed as input into the simulations under a typical value of $15 \mathrm{MPa}$, weak points in the marble can fail under stresses as low as $5 \mathrm{MPa}$, as has already been mentioned in section 4.2.

Figure 8 and Figure 9 convey the simulated stress field, total strain field and total deformation field. The areas of high stress concentration and high strains are magnified to elucidate how the loading conditions manifest themselves in the clamp specimens. For illustration purposes, the marble blocks are hidden from the images.

As can be deduced from Figure 8 and Figure 9, as well as from the data presented in Table 5 , the maximum stress in the system develops in the steel clamp/embedding material assembly, and only a fraction of this stress, roughly varying from 0.2 to 0.3 , is passed on as a maximum stress to the marble. It is also important to note that the stress that develops in the system is distinctly larger when lead has been used as an embedding material, though the fraction of the stress that is passed on to the marble is significantly lower, yet still larger than the values predicted when cement mortar has been used. The reduction in stress fraction passing to the marble is more prominent in the bending scenarios, which are more representative of probable actual loading conditions. The calculated development of higher stresses on the system due to embedding the clamps in lead could be misleading as far as the actual physical system is concerned. One of the assumptions of the model was that the entire space between the marble and the clamp would be filled by lead. If one takes into consideration the physicochemical properties of the system and the moulding techniques used, under atmospheric pressure, it is highly unlikely that voids will not be present in that

Table 5. Maximum stress calculated by finite element analysis of the discretised CADs for the two types of embedding material and the two directions of imposed acceleration leading to stretching and bending motions. The last column presents the results of the simulation for the corroded steel clamp, on which the growth of corrosion products has induced an intrinsic stress of $5 \mathrm{MPa}$ on the surrounding materials.

\begin{tabular}{|c|c|c|c|c|c|}
\hline $\begin{array}{l}\text { Embedding material (Intrinsic stress): } \\
\text { Acceleration direction / type of motion: }\end{array}$ & $\begin{array}{l}\text { Cement Mortar } \\
\text { Bending }\end{array}$ & $\begin{array}{l}\text { Cement Mortar } \\
\text { Stretching }\end{array}$ & Lead Bending & Lead Stretching & Lead (5 MPa) Bendin \\
\hline Max stress in system; $0.3 \mathrm{~g}(\mathrm{MPa})$ & 0.45 & 22.04 & 1.78 & 27.98 & 9.01 \\
\hline Max stress in system; $0.6 \mathrm{~g}(\mathrm{MPa})$ & 0.90 & 44.40 & 4.61 & 56.22 & 17.98 \\
\hline Max stress in system; $1.2 \mathrm{~g}(\mathrm{MPa})$ & 1.80 & 88.89 & 5.89 & 113.47 & 33.30 \\
\hline Max stress in marble; $0.3 \mathrm{~g}(\mathrm{MPa})$ & 0.15 & 4.94 & 0.28 & 6.23 & 8.87 \\
\hline Max stress in marble; $0.6 \mathrm{~g}(\mathrm{MPa})$ & 0.30 & 9.98 & 0.49 & 12.49 & 17.98 \\
\hline \multicolumn{6}{|l|}{ Linear coefficients \& coefficients of variation } \\
\hline Max stress in system $\left(\mathrm{MPa} \cdot \mathrm{m}^{-1} \cdot \mathrm{s}^{2}\right)$ & $1.50\left(R^{2}=1\right)$ & $74.03\left(R^{2}=1\right)$ & $5.49\left(R^{2}=0.90\right)$ & $94.33\left(R^{2}=1\right)$ & $22.73\left(R^{2}=0.98\right)$ \\
\hline Max stress in marble $\left(\mathrm{MPa} \cdot \mathrm{m}^{-1} \cdot \mathrm{s}^{2}\right)$ & $0.50\left(R^{2}=1\right)$ & $16.50\left(R^{2}=1\right)$ & $1.01\left(R^{2}=0.98\right)$ & $20.95\left(R^{2}=1\right)$ & $15.66\left(R^{2}=0.92\right)$ \\
\hline \multicolumn{6}{|c|}{ Estimated stress values for EPA of $0.16 \mathrm{~g}$ according to the linear coefficients } \\
\hline Max stress in system; $0.16 \mathrm{~g}(\mathrm{MPa})$ & 0.24 & 11.84 & 0.88 & 15.09 & 8.64 \\
\hline
\end{tabular}




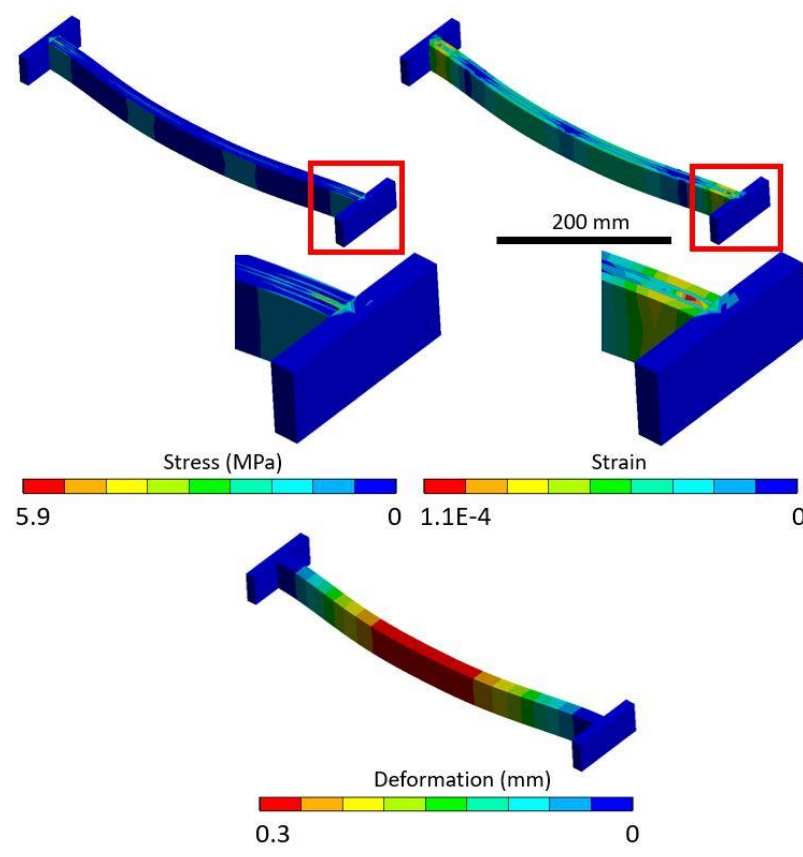

Figure 8. Characteristic marble block-steel clamp system with lead under bending at $1.2 \mathrm{~g}$. Equivalent von Mises stress, equivalent strains and total deformation are presented. For this case, the maximum stress concentration is observed at the core of the clamp, close to the intersection of the edges.

space. The very high surface tension of the molten lead would lead to non-wetting of the marble surfaces; thus, voids should be created along the edges of the nesting. Considering the high ductility of lead, the presence of empty spaces in the system could lead to dramatically lower values of developed stresses.

Another interesting observation is the linear relationship between the enforced acceleration and the maximum stress that developed in the system. The linear coefficients and the coefficients of determination are presented in the second part of Table 5. Unity R-squared values in all stretching scenarios and in bending scenarios with cement mortar as an embedding material indicate a linear correlation between the input and the output of the simulations. This is expected since the acceleration force over the area provides the applied stress; thus, the relationship between the applied stress and the acceleration force should be linear. In the case of the lead-metal-embedded clamp bending scenarios (both for non-corroded and for corroded steel) the simulation output deviates significantly from linearity when plotted against acceleration. This must be associated with the mechanical properties of the materials. Since the system is comprised of different layers of material, this discontinuity suggests a nonlinear relationship between stresses and forces. As can be observed in Table 4, the steel and the mortar have approximately the same Young's modulus, whereas the steel and the lead have a significant variance in the Young's modulus. Therefore, the nonlinearity will be alleviated in the case of the mortar, and it will be substantial for the lead. This explains the nonlinear relationship that is observed in the reported results on the bending of the lead.

Finite element calculations performed taking into account the development of steel corrosion products and the intrinsic stress induced have led to a large increase in the generated stress as a result of the acceleration stimulus. It is also notable that this is the only case, of those examined, in which, for an acceleration of $0.6 \mathrm{~g}$, the maximum stress induced on the system is applied to

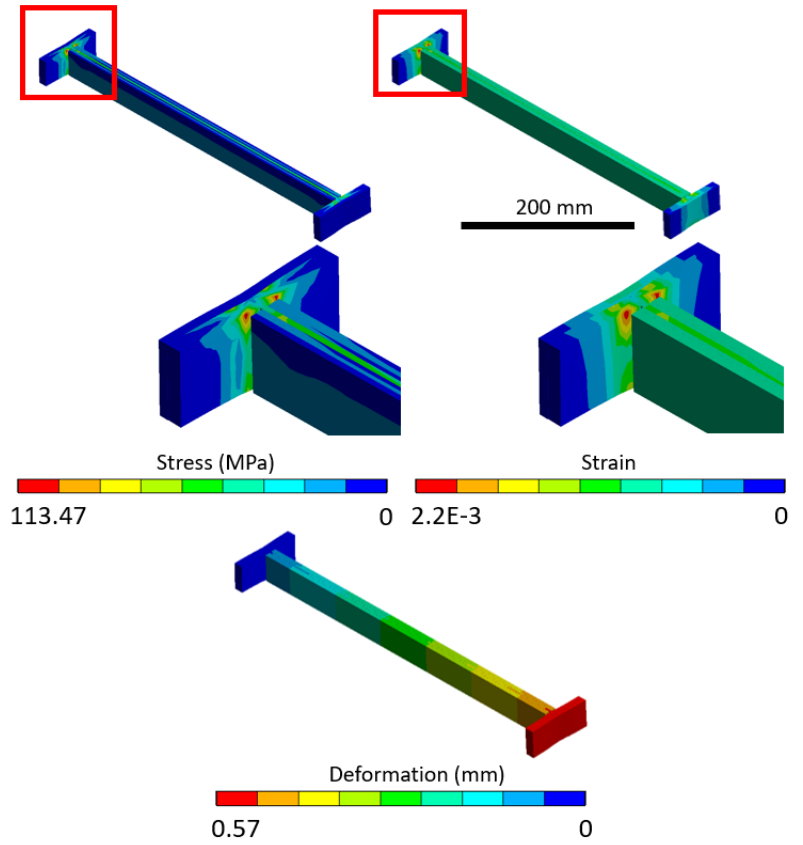

Figure 9. Characteristic marble block-steel clamp system with lead under stretching at $1.2 \mathrm{~g}$. The von Mises stress, total strain and deformation field are presented. High stress concentration is observed at the edges of the clamp.

the marble block. The fraction of stress that passes as maximum stress to the marble in this case is high, varying from 0.6 to 1. The system was simulated during bending, the most realistic scenario, and the results indicate that apart from the initial intrinsic $5 \mathrm{MPa}$ stress, the stress induced in the marble by the acceleration is more than 13-fold higher than the values calculated in the absence of the initial stress. Therefore, even during bending, corrosion can cause failure and crack formation in the marble, even before the thickness of the corrosion products formed can induce damage by mere crystallisation pressure. It is, again, only in the case of the corroded steel clamps that the maximum stress on the marble block is larger than 5 $\mathrm{MPa}$ when $0.16 \mathrm{~g}$ EPA is used as a stimulus. This point emphasises the significance of intrinsic stress to the modelling of the structure.

\section{CONCLUSIONS}

The examination of the three early $20^{\text {th }}$ century double-T clamps confirms that even though different types of Fe alloys (Carbon concentration range: $0.008-0.085 \%$ ) and metallurgical processing has been used, all joints exhibit low values of microhardness, tensile strength and Young's modulus of elasticity. During the fracture process, all the examined clamps are susceptible to a ductile fracture mechanism.

Clamp S.214, in particular, is a composite material produced by the cladding and folding of a hypoeutectoid steel and a lowcarbon iron alloy, which has very similar metallurgical characteristics to the original ancient clamps.

Clamp S.214 exhibits a higher thermodynamic tendency towards corrosion when immersed in a synthetic electrolyte simulating atmospheric pollutants. This particular clamp, when submitted to potentiodynamic electrochemical tests, undergoes more severe corrosion compared to the plain iron clamp and to a low-C steel clamp with added $\mathrm{Cr}$. These findings are associated with the clamp's higher carbon content and to its more complex 
metallurgical structure, which explains its corrosion state after its removal from the monument.

The finite element analysis simulations elucidated the differences induced by different materials and their state of conservation in relation to the response of the system during an earthquake. The main conclusions that should be highlighted are as follows:

- The use of lead as an embedding material reduces the fraction of the system maximum stress that is passed on as a maximum stress to the marble. The larger values of maximum stress calculated should significantly decrease if the physical model takes into consideration the voids that would be created during the moulding of molten lead.

- The intrinsic stresses that develop due to the formation of corrosion products drastically change the response of the system so that an otherwise harmless stimulus could lead to the fracture of the marble blocks, even for small thicknesses of corrosion product.

In general, this work demonstrates that it is possible to predict potential local damage with detailed information on the nature and conservation status of the materials. Finite element analysis can be performed on discretised CADs for unit cells, representative of specific existing parts of a monument, taking into consideration the physical dimensions, the materials and their state of conservation or pathology as well as existing intrinsic stresses, either due to corrosion or gravitational forces. Utilising as a stimulus the acceleration forces, as predicted by structural models for specific parts of the monument and combined with the appropriate boundary conditions, we can predict the mechanical response through finite element analysis modelling. This can be a valuable tool for tailored intervention for parts of the monument that require specific attention.

\section{AUTHORS CONTRIBUTION STATEMENT}

Z. Vangelatos designed the discretised CAD of the system, performed the finite element analysis in ANSYS and interpreted the results according to the static theory of beams. M. Delagrammatikas designed the physical models and correlated the simulation and linear regression analysis results, undertook most of the bibliographic research and performed part of the experimental work. O. Papadoloulou designed the electrochemical testing, conducted the related bibliographic research and performed most of the experimental work. C. Titakis carried out bibliographic research on the anticipated corrosion-product properties and performed part of the experimental work. Prof. P. Vassiliou had the original idea for this work, advised on every step of the design of the physical models and provided guidance on the interpretation of the results.

\section{ACKNOWLEDGEMENT}

The authors would like to thank the staff of YSMA for giving permission and providing the historic materials for the execution of the measurements presented in this short paper.

Special gratitude should be expressed to the staff of Chalyvourgiki S.A Quality Control Laboratory for performing the elemental analyses and the mechanical testing of the clamps.

Further acknowledgement is due to Michail KyritsisSpinoulas, who performed the Vickers micro-hardness testing and calculated the Young's modulus of elasticity as part of his master's thesis.

\section{REFERENCES}

[1] S. Kondaratos, The Parthenon as cultural ideal, in: The Parthenon and its Impact in Modern Times. P. Tournikiotis (editor). Melissa Publishing House, Athens, 1994, ISBN 960204019x, pp. 19-53.

[2] UNESCO Logo Toolkit: specifications for secondary logos. Online [Accessed 13 May 2020]

https://unesdoc.unesco.org/ark:/48223/pf0000191825

[3] Acropolis Restoration Service (YSMA). Online [Accessed 13 May 2020].

\section{https://ysma.gr/en/}

[4] M. Korres, C. Bouras, Study for the Restoration of the Parthenon, Ministry of Culture and Science - Acropolis Restoration Committee (ESMA), Athens, 1983. Online [Accessed 28 March 2020]

https://www.ysma.gr/en/open-access/publications/scientificpublications-list/

[5] A. V. Ramesh Kumar, R. Malasubramaniam, Corrosion product analysis of corrosion resistant ancient Indian iron, Corros. Sci. 40 (1998), pp. 1169-1178.

DOI: $10.1016 /$ S0010-938X(98)00024-9

[6] S. Leroy, M. Hedrickson, S. Baunais, E. Vega, T. Blanchet, A. Disser, E. Delque-Kollic, The ties that bind: archaeometallurgical typology of architectural crampons as a method for reconstructing the iron economy of Angkor, Cambodia (tenth to thirteenth c.), Archaeol. Anthropol. Sci. 10 (2018), pp. 2137-2157.

DOI: $10.1007 / \mathrm{s} 12520-017-0524-3$

[7] A. Orlandos, The Architecture of the Parthenon, Hellenic Archaeological Society, Athens, 1978, ISBN 978960703691. In Greek.

[8] T. Skoulikidis, Attaque atmosphérique (goujons en acier) et mésures é prendre, Proc. of the 2nd International Symposium on the Deterioration of Building Stones, Athens, Greece, 1976, pp. 347-349.

[9] S. Angelides, Replacement of steel connectors by titanium alloy, Proc. of the 2nd International Symposium on the Deterioration of Building Stones, Athens, Greece, 1976, pp. 351-352.

[10] T. Skoulikidis, P. Vassiliou, Corrosion and conservation of building materials of monuments; the Acropolis case, Corros. Rev. 17 (1999), pp. 295-332.

DOI: $10.1515 /$ CORRREV.1999.17.5-6.295

[11] A. Miltiadou-Fezans, E. Papakonstantinou, K. Zambas, A. Panou, K. Frantzikinaki, Design and application of hydraulic grouts of high injectability for the structural restoration of the column drums of the Parthenon Opisthodomos, WIT Trans. Built Env. 83 (2005), pp. 461-471.

DOI: $\underline{10.2495 / \text { STR050441 }}$

[12] H. T. Mantis, C. C. Repapis, C. S. Zerefos, I. Ziomas, Assessment of the potential for photochemical air pollution in Athens: a comparison of emissions and air-pollutant levels in Athens with those in Los Angeles, J. Appl. Meteorol. 31 (1992), pp. 1467-1476. DOI: $10.1175 / 1520-0450(1992) 031<1467: A O T P F P>2.0 . C O ; 2$

[13] K. Eleftheriadis, D. Balis, I. Ziomas, I. Colbeck, N. Manalis, Atmospheric aerosol and gaseous species in Athens, Greece, Atmos. Environ. 32 (1998), pp. 2183-2191.

DOI: $10.1016 /$ S1352-2310(97)00412-3

[14] Greek Seismic Regulation EAK 2000, OASP, Athens, 2000. Online [Accessed 28 March 2021] https://www.oasp.gr/node/8

[15] A. Elenas, Athens earthquake of 7 September 1999: intensity measures and observed damages, ISET J. Earthq. Technol. 40 (2003), pp. 77-97. Online [Accessed 28 March 2021] http://home.iitk.ac.in/ vinaykg/Iset 40 tn.pdf

[16] I. N. Psycharis, Seismic vulnerability of classical monuments, in: K. Pitilakis (editor). Recent Advances in Earthquake Engineering in Europe. ECEE 2018. Geotechnical, Geological and Earthquake Engineering, vol. 46, Springer, Cham, 2018 , ISBN 978-3-31975740-7, pp. 563-582

[17] I. N. Psycharis, A. E. Drougas, M. E. Dasiou, Seismic behaviour of the walls of the Parthenon, a numerical study, in: M. 
Papadrakakis, M. Fragiadakis, N. Lagaros (editors). Computational Methods in Earthquake Engineering. Computational Methods in Applied Sciences, vol 21. Springer, Dordrecht, 2011, ISBN 97894-007-0052-9, pp. 265-283.

[18] E. Ganniari-Papagerorgiou, Joining fragmented epistyles using threaded titanium bars: a numerical analysis, Strain 45 (2009), pp. 445-455.

DOI: $10.1111 / \mathrm{i} .1475-1305.2008 .00507 . \mathrm{x}$

[19] E. D. Pasiou, S. K. Kourkoulis, Mechanical response of marble epistyles under shear: numerical analysis using an experimentally validated model, Journal of Mechanical Behaviour of Materials 27 (2018), 20180023.

DOI. 10.1515/imbm-2018-0023

[20] E. Toumbakari, Analysis and interpretation of the structural failures of the orthostate in the northern wall of the Athens Parthenon, Strain 45 (2009), pp. 456-467. DOI: $10.1111 / \mathrm{j} .1475-1305.2008 .00529 . \mathrm{x}$

[21] D. Chicot, J. Mendoza, A. Zaoui, G. Louis, V. Lepingle, F. Roudet, J. Lesage, Mechanical properties of magnetite $\left(\mathrm{Fe}_{3} \mathrm{O}_{4}\right)$, hematite $\left(\alpha-\mathrm{Fe}_{2} \mathrm{O}_{3}\right)$ and goethite $(\alpha-\mathrm{FeO} \cdot \mathrm{OH})$ by instrumented indentation and molecular dynamics analysis, Mater. Chem. Phys. 129 (2011), pp. $862-870$

DOI: $10.1016 /$ i.matchemphys.2011.05.056
[22] A. Ouglova, Y. Berthaud, M. François, F. Foct, Mechanical properties of an iron oxide formed by corrosion in reinforced concrete structures, Corros. Sci. 48 (2006), pp. 3988-4000. DOI: $10.1016 /$ i.corsci.2006.03.007

[23] S. Caré, Q. T. Nguyen, V. L'Hostis, Y. Berthaud, Mechanical properties of the rust layer induced by impressed current method in reinforced mortar, Cement and Concrete Research 38 (2008), pp. 1079-1091.

DOI: $\underline{10.1016 / \text { i.cemconres.2008.03.016 }}$

[24] C. Conophagos, Physical Metallurgy, Book II Alloys, SelfPublication, Athens, 1965, p. 157. In Greek.

[25] G. Varoufakis, The iron clamps and dowels from the Parthenon and Erechtheion, The Journal of Historical Metallurgy Society 26 (1992), pp. 1-18.

[26] G. Varoufakis, The rapid development of technology in making iron clamps of three ancient temples in the archaic and classical period, J. Chem. Eng. 6 (2012), pp. 1136-1141. Online [Accessed 28 March 2021]

http://www.davidpublisher.org/index.php/Home/Article/index ?id=16422.html

DOI: $10.17265 / 1934-7375 / 2012.12 .012$ 